\title{
Analysis and Prediction of Environmental Pollution Control of China's Investment Based on Grey Prediction and Multiple Regression
}

\author{
Zhan-Hua ZHANG ${ }^{1, \text { a }}$, Xiao-Hong LIU ${ }^{2, \text { b, }}$, Chun-Yan ZHANG ${ }^{3, c}$ \\ ${ }^{1}$ Institute of Management, Southwest University for Nationalities, Chengdu, Sichuan, China \\ ${ }^{2}$ Institute of Management, Southwest University for Nationalities, Chengdu, Sichuan, China \\ ${ }^{3}$ Financial Department, Jinan University, Guangzhou, Guangdong, China \\ a954331740@qq.com, 'b Ixhdoctor@126.com, '562451756@qq.com \\ ${ }^{*}$ Corresponding author
}

Keywords: Grey prediction, Multiple regression, Investment in environmental pollution control, Prediction.

\begin{abstract}
According to the future uncertainty of investment scale of pollution control in China, in order to predict the variable value, Grey prediction model is used to eliminate the noise pollution which is from the variable data of investment in environmental pollution control. Then through multiple regression models and the variable data, to predict and analyze the future of China's environmental pollution control investment.
\end{abstract}

\section{Introduction}

The intensity and effect of treatment of environmental pollution has become an important index to measure the health and sustainable development of China's economic society. Pollution treatment cost of environmental pollution control need to invest a huge scale. Therefore, it is important to forecast and Analysis on the investment of environmental pollution treatment. In recent years, scholars and experts are becoming more and more research on the investment of environmental pollution treatment. Zheng Zhi-xia (2013) and Chang Zhe-min (2011) [1] analyzed the distribution of investment structure and space pollution abatement investment. A reasonable application and how to deal with the problems of environmental pollution control investment in the improvement of regional environment were analyzed by Dong Xiao-lin, Zhou Jing (2008) [2] and Dong Wen-fu (2008) [3]. Liu Tao (2012) and Lu Fang-yuan, Li Kui (2007) [4], using data envelopment analysis method evaluated the efficiency of environmental pollution control investment in Fujian province. The experts conduct the research from the different perspectives. But the quantitative prediction of analysis of research on environmental pollution control of China's investment by which is used mathematical model is less. In order to improve the accuracy of the prediction results for the investment of environmental pollution treatment, the combination forecasting method is widely used in prediction and analysis of various indexes by the method of grey forecasting and regression analysis. Han Jing (2012) [5] and Li Yong (2012) [6] analysis of the combined application of grey prediction and regression analysis, further proved the combination forecast model is more accurate. The water demand of Shenzhen Dapeng Peninsula was predicted by Zhang Qian, Shen Li (2010) [7] with the analysis of grey theory and regression. According to the future uncertainty of investment scale of pollution control in China, in order to predict the variable value, Grey prediction model is used to eliminate the noise pollution which is from the variable data of investment in environmental pollution control. Then through multiple regression models and the variable data, to predict and analyze the future of China's environmental pollution control investment.

\section{Select the appropriate model and method}

\section{Gray prediction or $\mathrm{G}(1,1)$ prediction model}

Grey prediction method believe that no matter how complicated the objective system, it has relevance, orderly and overall functional. The grey prediction model will generate a new 
sequence data by the original data sequence accumulation, and the establishment of a corresponding prediction model. The predicted data processing result is obtained through inverse prediction data generation model values. Grey theory can effectively predict the data of few samples, be out of order and weak noise case. This paper uses $G(1,1)$ model to predict the variable data which will impact on environmental pollution control investment. The use of $G(1,1)$ model to forecast the basic steps are as follows [8]:

Assume the existence of the original data $x^{(0)}=\left(x^{(0)}(1), x^{(0)}(2), \ldots, x^{(0)}(n)\right), n$ says the number of data. Then they $\mathbf{x}^{(0)}$ are accumulated, to obtain a new data columns: $x^{(1)}=\left(x^{(1)}(1), x^{(1)}(2), \ldots, x^{(1)}(n)\right)$. Superposition is intended for less volatility and stochastic of random sequence, and among them, $x^{(1)}(k)=\sum_{i=1}^{k} x^{(0)}(i), k=1,2, \cdots, n$. So A differential equation of order $\mathbf{x}^{(1)}(\mathrm{t})$ can be constructed:

$$
\frac{d x^{(1)}}{d t}+a x^{(1)}=u
$$

Type (1), $a$ is the development coefficient, $u$ is grey action, both of them are undetermined parameters and structure matrix $\hat{\mathrm{a}}=(\mathrm{a}, \mathrm{u})^{\top}$. As long as the parameters of the $\mathrm{a}$ and $\mathrm{u}$ solution are solved. We can find out the prediction of values $x^{(1)}(t)$ and $x^{(0)}$. Then the prediction of value $x^{(0)}$ will work out. According to the least square method to solve the approximate value of grey parameter $\hat{\mathrm{a}}: \hat{\mathrm{a}}=\left(\mathrm{A}^{\mathrm{T}} \mathrm{A}\right)^{-1} \mathrm{~A}^{\mathrm{T}} \mathrm{B}_{\mathrm{n}}$.

$$
\mathrm{A}=\left[\begin{array}{c}
0.5\left(\mathrm{x}^{(1)}(1)+\mathrm{x}^{(1)}(2)\right) \\
0.5\left(\mathrm{x}^{(1)}(2)+\mathrm{x}^{(1)}(3)\right) \\
\ldots \\
0.5\left(\mathrm{x}^{(1)}(\mathrm{n}-1)+\mathrm{x}^{(1)}(\mathrm{n})\right)
\end{array}\right], \mathrm{B}_{\mathrm{n}}=\left[\begin{array}{c}
\mathrm{x}^{(0)}(2) \\
\mathrm{x}^{(0)}(3) \\
\ldots \\
\mathrm{x}^{(0)}(\mathrm{n})
\end{array}\right] \text {,then make the Approximate values of } \hat{a} \text { to }
$$

the type (1), we can find out that: $\hat{x}^{(1)}(t+1)=\left(x^{(0)}(1)-\frac{u}{a}\right) e^{-a t}+\frac{u}{a}$. Similarly, $\hat{x}^{(1)}(t+1)$ is an approximate expression. Then we can compute the approximate expression of $x^{(0)}(t+1)$ : $\hat{\mathbf{X}}^{(0)}(\mathrm{t}+1)=\hat{\mathbf{x}}^{(1)}(\mathrm{t}+1)-\hat{\mathbf{x}}^{(1)}(\mathrm{t})$, Finally, we can get the predictive value of $\mathrm{x}^{(0)}(\mathrm{t})$.

\section{Selection of regression model}

According to the provisions of the State Statistical Bureau and the Ministry of environmental protection, environmental protection investment in China mainly refers to the investment in environmental pollution control. Investment in environmental pollution control mainly includes the cityenvironmental infrastructure investment, investment in the treatment of industrial pollution and the "three simultaneous" project investment in environmental protection [9]. Therefore, this paper uses the MATLAB software to fit function, and based on the least square method, finite difference method, the regression equation about the pollution of the environment of investment will be obtained and shown as follows:

$$
\hat{Y}_{t}=2.40738 A_{t}^{0.57315} B_{t}^{0.12686} C_{t}^{0.3126}
$$

Type (2), $\hat{Y}_{t}$ represents the environmental pollution control of China'sinvestment in $t$ year. $A_{t}$ represents China's urban environmental infrastructure construction investment in in $t$ year. $B_{t}$ represents the prevention and control of pollution source of China's industrial investment in $t$ year. The 
$\mathrm{C}_{\mathrm{t}}$ represents the "three simultaneous" project environmental protection investment in $\mathrm{t}$ year. The unit of all variables in type (2) is one hundred million yuan.

\section{Analysis and prediction of environmental pollution control investment in china}

In this paper, data from Chinese "Statistical Yearbook"which is from 2002 to 2012, the data of Chinese city environmental infrastructure investment, industrial pollution control investment and construction projects "three simultaneous" investment in environmental protection as shown in Table 1:

Table 1 The related index data of environmental pollution control investment 2002-2012 year

\begin{tabular}{|c|c|c|c|c|}
\hline Amount & $\begin{array}{c}\text { Total investment in } \\
\text { environmental } \\
\text { pollution } \\
\text { control (100 } \\
\text { million yuan) }\end{array}$ & $\begin{array}{l}\text { Urban environm } \\
\text { ental } \\
\text { infrastructure } \\
\text { construction } \\
\text { investment(100 } \\
\text { million yuan) }\end{array}$ & $\begin{array}{l}\text { Investment in the } \\
\text { treatment of } \\
\text { industrial } \\
\text { pollution ( } 100 \\
\text { million yuan) }\end{array}$ & $\begin{array}{l}\text { Construction } \\
\text { project "three } \\
\text { simultaneous" i } \\
\text { nvestment in } \\
\text { environmental } \\
\text { protection (100 } \\
\text { million yuan) }\end{array}$ \\
\hline 2002 & 1367.2 & 789.1 & 188.4 & 389.7 \\
\hline 2003 & 1627.7 & 1072.4 & 221.8 & 333.5 \\
\hline 2004 & 1909.8 & 1141.2 & 308.1 & 460.5 \\
\hline 2005 & 2388.0 & 1289.7 & 458.2 & 640.1 \\
\hline 2006 & 2566.0 & 1314.9 & 483.9 & 767.2 \\
\hline 2007 & 3387.3 & 1467.5 & 552.4 & 1367.4 \\
\hline 2008 & 4937.0 & 2247.7 & 542.6 & 2146.7 \\
\hline 2009 & 5258.4 & 3245.1 & 442.6 & 1570.7 \\
\hline 2010 & 7612.2 & 5182.2 & 397.0 & 2033.0 \\
\hline 2011 & 7114.0 & 4557.2 & 444.4 & 2112.4 \\
\hline 2012 & 8253.5 & 5062.7 & 500.5 & 2690.4 \\
\hline
\end{tabular}

Data sources: "Chinese Statistical Yearbook". http://www.stats.gov.cn/tjjj/ndsj/

\section{Forecast of China's investment in environmental pollution control index}

G $(1,1)$ grey prediction is used to the original data of Table 1 by using MATLAB software, and the prediction results of 2013-2016 years as shown in Table 2.

We can see from Table 2, The average relative error of our city environmental infrastructure investment, industrial pollution control investment and construction projects "three simultaneous" investment in environmental protection was 3.9\%, $0.13 \%$ and $3.47 \%$ respectively. Due to the relative error of the simulation values and the actual values are very small every year except 2011, and the average relative error is very small too. Therefore, it is a feasible prediction model. The forecast data of related indicators of environment pollution control investment from 2013 to 2016 year as shown in Table 3. 
Table 2 grey prediction results of China's investment in environmental pollution control index

\begin{tabular}{|c|c|c|c|c|c|}
\hline Index & Year & $\begin{array}{l}\text { actual } \\
\text { value }\end{array}$ & $\begin{array}{c}\text { analog } \\
\text { value }\end{array}$ & Residuals & $\begin{array}{l}\text { relative } \\
\text { error }\end{array}$ \\
\hline \multirow{4}{*}{$\begin{array}{c}\text { Urban environmental } \\
\text { infrastructure construction } \\
\text { investment( } 100 \text { million } \\
\text { yuan) }\end{array}$} & 2009 & 3245 & 3245 & 0 & $0.0 \%$ \\
\hline & 2010 & 5182 & 4996 & -186 & $-3.6 \%$ \\
\hline & 2011 & 4557 & 4934 & 376 & $8.3 \%$ \\
\hline & 2012 & 5063 & 4872 & -191 & $-3.8 \%$ \\
\hline \multirow{4}{*}{$\begin{array}{l}\text { Investment in the treatment } \\
\text { of industrial pollution ( } 100 \\
\text { million yuan) }\end{array}$} & 2009 & 443 & 443 & 0 & $0.0 \%$ \\
\hline & 2010 & 397 & 396 & -1 & $-0.2 \%$ \\
\hline & 2011 & 444 & 445 & 0 & $0.1 \%$ \\
\hline & 2012 & 501 & 499 & -1 & $-0.2 \%$ \\
\hline \multirow{4}{*}{$\begin{array}{l}\text { Construction project "three } \\
\text { simultaneous" investment in } \\
\text { environmental } \\
\text { protection ( } 100 \text { million } \\
\text { yuan) }\end{array}$} & 2009 & 1571 & 1571 & 0 & $0.0 \%$ \\
\hline & 2010 & 2033 & 1942 & -91 & $-4.5 \%$ \\
\hline & 2011 & 2112 & 2255 & 143 & $6.8 \%$ \\
\hline & 2012 & 2690 & 2619 & -72 & $-2.7 \%$ \\
\hline
\end{tabular}

Table 3 The forecast data of related indicators from 2013 to 2015 year

\begin{tabular}{|c|c|c|c|}
\hline $\begin{array}{c}\text { Andeunt } \\
\text { inyested }\end{array}$ & $\begin{array}{c}\text { Urban environmental } \\
\text { infrastructure } \\
\text { construction } \\
\text { investment(100 million } \\
\text { yuan) }\end{array}$ & $\begin{array}{c}\text { Investment in the } \\
\text { treatment of } \\
\text { industrial } \\
\text { pollution (100 } \\
\text { million yuan) }\end{array}$ & $\begin{array}{c}\text { Construction } \\
\text { project "three } \\
\text { simultaneous" investme } \\
\text { nt in environmental } \\
\text { protection (100 million } \\
\text { yuan) }\end{array}$ \\
\hline 2013 & 4811.1 & 560.8 & 3040.4 \\
\hline 2014 & 4750.9 & 629.7 & 3530.3 \\
\hline 2015 & 4691.5 & 707.1 & 4099.2 \\
\hline 2016 & 4632.8 & 794.0 & 4759.7 \\
\hline
\end{tabular}

To validate the regression equation and Forecast of China's environmental pollution control investment

According to the equation (2), we can get the predicted values of China's environmental pollution control of investment which is from 2002 to 2012 year. At the same time, the regression equation is tested, the results are shown in Table 4.

According to Table 4, predicted values by the regression equation of environmental pollution control investment is very small. The relative error of the actual value and the average relative error is only $0.9 \%$. The relationship between the predicted data by the combined model and the actual value of the Investment in environmental pollution control from 2002 to 2012 year has be shown in Fig.1. Therefore, the model can be used to predict. Having the data in Table 3 into type (2), then Predicted values of investment in environmental pollution control from 2013 to 2016 year in China would be obtained in Table 5. 
Table 4 The test table of regression equation

\begin{tabular}{ccccc}
\hline Year & $\begin{array}{c}\text { actual } \\
\text { value(100 } \\
\text { millionyuan) }\end{array}$ & $\begin{array}{c}\text { analog } \\
\text { value(100 } \\
\text { millionyuan) }\end{array}$ & $\begin{array}{c}\text { Residuals } \\
(100 \\
\text { millionyuan) }\end{array}$ & relativeerror $(\%)$ \\
\hline 2002 & 1367.2 & 1382.1 & -14.90 & -1.09 \\
2003 & 1627.7 & 1602.3 & 25.39 & 1.56 \\
2004 & 1909.8 & 1914.9 & -5.06 & -0.26 \\
2005 & 2388.0 & 2394.2 & -6.20 & -0.26 \\
2006 & 2566.0 & 2579.7 & -13.73 & -0.54 \\
2007 & 3387.3 & 3347.0 & 40.27 & 1.19 \\
2008 & 4937.0 & 4909.5 & 27.53 & 0.56 \\
2009 & 5258.4 & 5355.6 & -97.17 & -1.85 \\
2010 & 7612.2 & 7487.7 & 124.46 & 1.63 \\
2011 & 7114.0 & 7141.3 & -27.22 & -0.38 \\
2012 & 8253.5 & 8305.0 & -51.50 & -0.62 \\
\hline
\end{tabular}

Table 5 forecast value of investment in environmental pollution control, (100 million yuan)

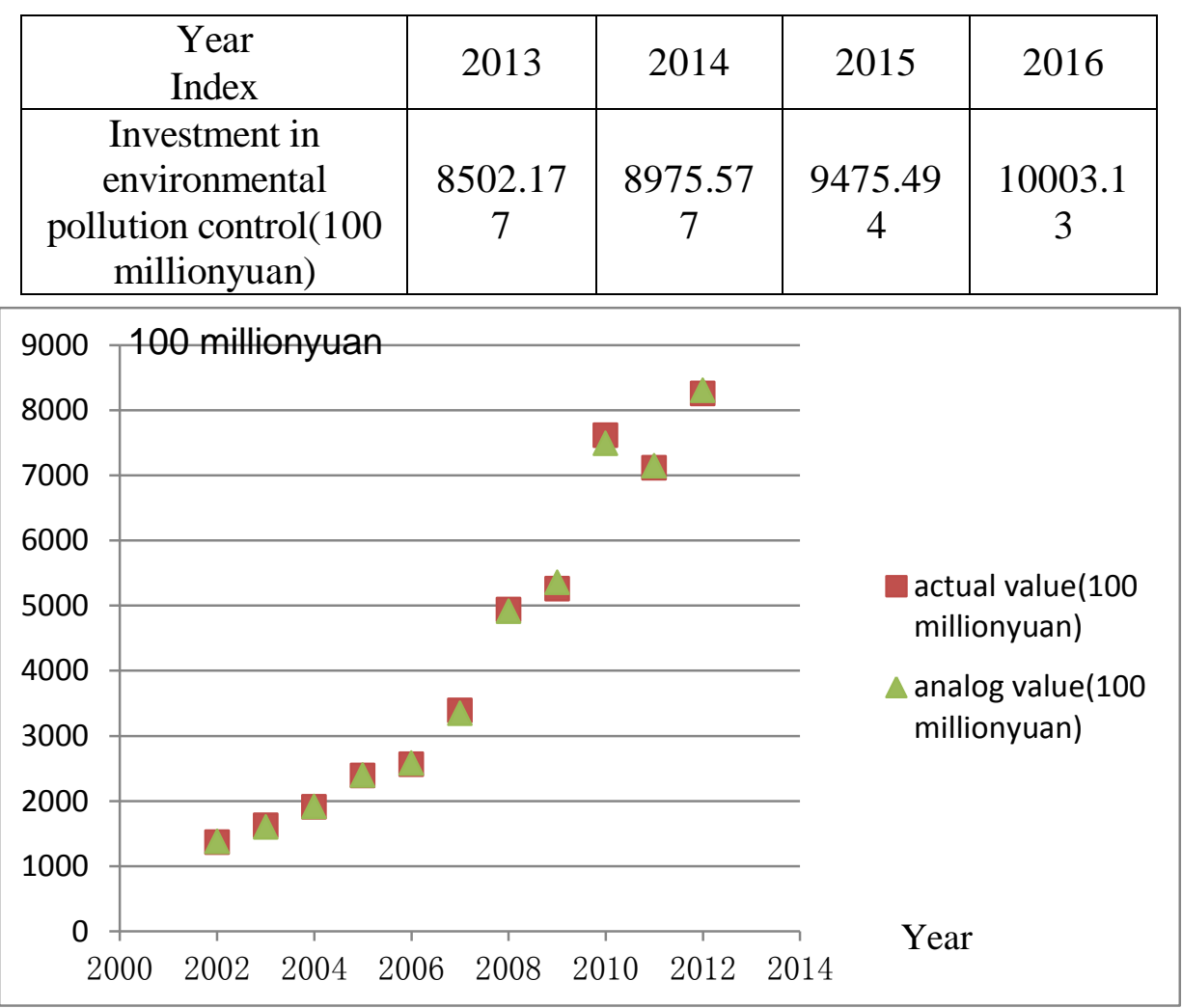

Fig.1 the forecast value and actual value of environmental pollution of our investment from 2002 to 2012 year

\section{Conclusion}

Our country is facing total investment in environmental pollution control is insufficient from the nationwide situation. Therefore, the forecast of investment in environmental pollution control in China is a reference when the government in determining it in the future. Regression analysis is a very important quantitative statistical analysis method which can effectively measure the degree of correlation between variables, a concrete manifestation of rule and so on. The regression analysis requires a large number of sample data for analysis, But grey prediction is still able to predict accurately 
in these situations of small samples and shows no significant statistical rule. It can improve the prediction accuracy and reduce the relative error with the effective combination of the two methods.

\section{Acknowledgements}

This paper is the periodical results of Postgraduate Innovation Research Key Project in Southwest University for Nationalities "The prediction about the level of consumption of urban residents which is based on multiple regression and GM $(1,1)$ model" (CX2014SZ05).

\section{Literature References}

[1] Zheng Zhi-xia. Analysis and Comments of Investment in Environmental Pollution Treatment during the Eleventh Five-Year in Anhui province [J]. Journal of Anhui Agri. Sci, 2013, 41(4):76-81.

[2] Dong Xiao-lin, Zhou Jing. The analysis of investment structure in district environment pollution control [J]. Journal of Northwest University (Natural Science), 2008, 38(2):295-299.

[3] Dong Wen-fu, Fu De-qian. Analysis of Development and Problem of the Investment in the Treatment of Environmental Pollution in China [J]. Envrionment Monitoring In China,2008,24(4):87-98.

[4] Lu Fang yuan, Li Kui. The Analysis of Panel Data on the Relationship between Pollution Treatment Investment and the Growth of Industrial Economy [J]. Systems Engineering, 2007,25(9):85-90.

[5] Han Jing, Wang Shu-hong. The improved grey multiple regression model [J]. Statiscs and Decision, 2010, (13):18-19.

[6] Li Yong. Research on the Parameters Theory and Application of the Linear Regression Model Based on the Gray System [J]. Journal of applied Statistics and Management, 2013(3):440-446.

[7] Zhang Qian, Shen Li. Combination forecast research on water demand based on the grey theory and regression analysis [J]. Journal of Northwest A\&F University(Nat. Sci. Ed), 2010(8):223-227.

[8] Zhuo Jin-wu, Wei Yong-sheng. Application of MATLAB in mathematical modeling [M].Beijing: Beijing University of Aeronautics and Astronautics Press, 2011(4):30-32.

[9] The people's Republic of China Statistics Bureau. http://www.stats.gov.cn. 